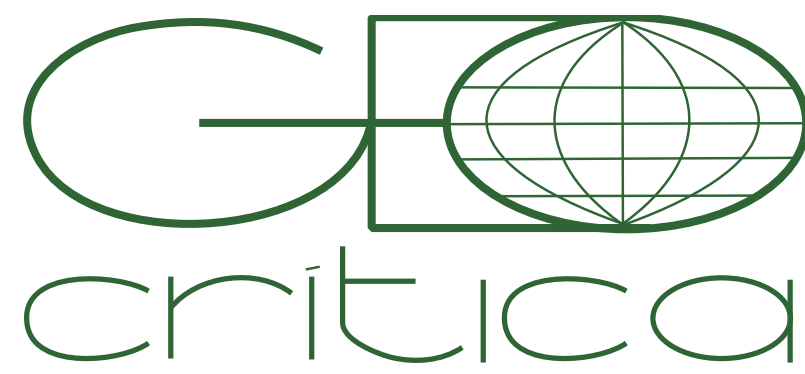

\section{Scripta Nova}

Revista Electrónica de Geografía y Ciencias Sociales Universitat de Barcelona

ISSN: $1138-9788$

Vol. 25, Núm. 2 (2021), p. 105-129

\title{
POLÍGONO SUR EN SEVILLA. HISTORIA DE UNA MARGINACIÓN URBANA Y SOCIAL
}

\author{
Francisco José Torres Gutiérrez \\ Universidad Pablo de Olavide (Sevilla). \\ Correo electrónico: fjtorgut@upo.es
}

Recibido: 15 enero 2021; Devuelto para correcciones: 14 abril 2021; Aceptado: 10 mayo 2021

\section{Polígono sur en Sevilla. Historia de una marginación urbana y social (Resumen)}

Polígono Sur de Sevilla, considerado uno de los barrios más pobres y con mayores niveles de conflictividad social en el estado español, presenta graves problemáticas de índole social, urbana y ambiental. Las referencias estadísticas, los análisis efectuados en distintos estudios e informes y la propia expresión de su paisaje urbano lo convierten, sin ninguna duda, en uno de los casos extremos de la desigualdad urbana en España. Sus acusadas desventajas actuales enraízan en la concentración de población empobrecida que representó el proyecto urbanístico original: un polígono de viviendas sociales en la periferia de la ciudad, construido fundamentalmente entre los años 60 y 70, en el que se realojaron muchas familias humildes de distintas procedencias, desahuciadas de barrios históricos o provenientes de poblados chabolistas, refugios 0 infraviviendas, que sufre con mayor intensidad los diferentes momentos de crisis y que, durante largos periodos de tiempo, es desatendido por la Administración. Palabras clave: Desigualdad urbana; Segregación social; Polígono Sur; Sevilla

\section{Polígono Sur in Seville. History of urban and social marginalization (Abstract)}

The Polígono Sur estate in Seville, considered one of the poorest neighbourhoods with the highest levels of social conflict in Spain, presents a number of serious social, urban, and environmental problems. Statistical references, analyses carried out in different studies and reports, and even the expression of its urban landscape make it, without any doubt, one of the most extreme cases of urban inequality in Spain. Its current marked disadvantages are rooted in the concentration of an impoverished population represented by the original urban project: a social housing estate on the outskirts of the city, built fundamentally between the 1960s and 70s, in which many poor families of different origins were rehoused, having been evicted from historic neighbourhoods or shanty towns, shelters or substandard housing. This neighbourhood has experienced different periods of crisis with acute intensity, and, for long periods of time, it has been neglected by the Government. Key words: Urban inequality; Social segregation; Polígono Sur; Seville 
Según los datos de renta divulgados anualmente por el I.N.E., el Polígono Sur de Sevilla suele situarse en el primer o segundo lugar dentro de la lista de barrios más pobres de España, posición disputada habitualmente con Tres Barrios, también de la misma ciudad. Sus niveles de conflictividad, especialmente en la zona más degradada, tienen eco en frecuentes reportajes televisivos y en otros medios, no sin cuestionables tintes sensacionalistas que redundan en una imagen general estereotipada. Ha sido valorado como un caso significativo de los fracasos de la política de vivienda pública, objeto de intervención de múltiples proyectos urbanos y programas sociales que han supuesto grandes inversiones económicas. Los numerosos informes de la Administración e investigaciones académicas han aportado duros diagnósticos de su problemática social, urbanística y ambiental, aunque también se ha planteado su profunda complejidad en otros trabajos, reportajes audiovisuales e incluso novelas ${ }^{1}$ que han desvelado la noble historia de su movimiento vecinal, experiencias personales y colectivas de superación o el prestigio de su vertiente gitana, cultural y flamenca.

Presentado así, como uno de los casos extremos de la desigualdad urbana en España, se aborda en este texto un doble análisis de la realidad de Polígono Sur. El objetivo del mismo es el de argumentar la gravedad de esta desigualdad y caracterizar el modo en que se ha ido consolidando en el tiempo. Observamos así su trayectoria desde una perspectiva cuantitativa, descriptiva y comparada, apoyándonos en trabajos estadísticos elaborados con distintos tratamientos y escalas geográficas, e interpretamos, desde un enfoque más cualitativo y complejo, el modo en que se suceden e interrelacionan, a lo largo de las diferentes etapas en que puede estructurarse su historia, los aspectos y procesos que mantienen sus desventajas y tendencias hacia la exclusión. La primera etapa que delimitamos acoge todo el proceso de construcción, en sus distintas fases, que conforma el tejido residencial completo de esta área urbana, desde 1964 a 1981, mientras que las siguientes se establecen a partir de acontecimientos trascendentes y dinámicas determinadas que, en el sentido indicado, inciden en el devenir de su población y sus condiciones de vida.

Los datos recientes siguen siendo expresivos de una acusada desigualdad, sobre todo en algunas de sus barriadas, fenómeno que se vincula estrechamente con su segregación social y los mecanismos urbanísticos y residenciales que han propiciado su aislamiento y retroalimentación como espacio destinado a los grupos sociales y colectivos más desfavorecidos y marginados. Tal situación, que debemos contextualizar en las circunstancias particulares de Andalucía, región muy dependiente de coyunturas generales de carácter político y económico (Arenas 2016), puede ser mejorada o aliviada desde la acción del movimiento vecinal, del tejido asociativo y por las intervenciones llevadas a cabo por las Administraciones. La creación del Comisionado del Polígono Sur y el desarrollo del Plan Integral han sido respuestas significativas al respecto.

A tenor de lo anterior, la tesis que aquí se plantea se apoya teóricamente en la clásica dialéctica socio-espacial argumentada desde el prisma neomarxista de autores como Harvey

1 Ponemos como ejemplo la novela de Manuel Machuca "Tres mil viajes al sur", publicada en 2016 por la editorial Anantes (http://www.tresmilviajesalsur.es/). 
(1977) y Soja (1980), y se concreta en un territorio específico en el que se considera la particularidad de su evolución histórica. A partir de la categorización conceptual propuesta en Capel (2003), observamos cómo los elementos físico-espaciales (urbs), el capital social y comunitario (civitas) y la movilización ciudadana y acción institucional (polis), no han propiciado suficientes cauces de transformación; más bien han ido convergiendo, con distintas orientaciones en cada momento, en la perpetuación del deterioro del barrio -si no general, sí relativo y focalizado- y en el agravamiento de su estigma.

\section{Denominación, proyecto y localización}

Es importante reparar en el nombre de Polígono Sur y en su carencia, desde un punto de vista semántico, de atributos históricos o socioculturales. Tras el sentido puramente geométrico de su primera acepción oficial, el concepto remite al modelo urbanístico que le dio origen, es decir, a la unidad espacial delimitada como polígono de vivienda social, una actuación pública planteada para dar cobijo a población inmigrada de distintas procedencias. Tal desvinculación nominal con el paisaje en el que se sitúa, algo propio de la mentalidad tecnócrata de la época, se adjetiva por la orientación geográfica que obtiene en el marco del municipio. Sur define así la situación territorial frente a otros polígonos que nacen en la periferia.

Por otro lado, debemos tener en cuenta un hecho que puede parecer paradójico: el actual objetivo institucional de difundir el topónimo original del Polígono Sur frente a las connotaciones que, con el tiempo, ha ido adquiriendo la denominación de Tres Mil Viviendas, un nombre que no solo no corresponde con la realidad territorial a la que comúnmente se atribuye (tres mil es el número de viviendas de Murillo, una de las seis barriadas) sino que, además, se trata de un topónimo que surge de la mera y fría descripción cuantitativa de dicha actuación urbanística. Las Tres Mil, que se emplea con muy diferentes significados e intenciones, evoca en general el carácter degradado y conflictivo de esta parte de la ciudad.

Como se ha dicho, el barrio responde de un modo paradigmático al modelo urbanístico y social del polígono de viviendas sociales que se extiende entre los años 60 y 70 en la periferia de muchas ciudades industriales españolas. Frente a los polígonos construidos durante los 50 y parte de los 60, con una habitabilidad mermada, estas promociones mejoran considerablemente los estándares arquitectónicos, así como los espacios públicos y equipamientos, al menos sobre el plano. Por otro lado, la morfología urbana que caracteriza a las barriadas más recientes (Murillo, Martínez Montañés, Antonio Machado y Paz y Amistad) genera espacios libres, de superficies compuestas por materiales duros y monótonos, que carecen de un diseño y vocación determinada, lo que da lugar a una confusión entre espacios públicos, comunitarios y privados, a que afloren conflictos en relación con su apropiación y que no se asuman responsabilidades respecto a su cuidado. Así mismo, la imagen desolada que transmite este paisaje urbano, especialmente cuando su deterioro se hace evidente, da lugar a que el visitante se mueva con miedo en un espacio aparentemente abandonado.

La localización de Polígono Sur dentro del tejido de la ciudad, si se observa en el contexto territorial en el que se produce su nacimiento, se convierte en el primer factor que, 
de manera notable, va a condicionar su integración en la estructura urbana de la ciudad. Como refleja la figura 1, donde se muestra la fotografía aérea de 1956, su emplazamiento periférico queda subrayado por los límites que establecen los elementos naturales y urbanísticos que han ido reconfigurándose hasta la actualidad:

- Por la parte norte discurre el trazado del antiguo cauce del arroyo del Tamarguillo, entonces canalizado y luego convertido en la ronda del mismo nombre. En ese entorno se ejecuta el Parque José Celestino Mutis, junto a la barriada La Oliva, convirtiendo este flanco en el más permeable de toda el área.

- El límite por el este estaba marcado por la vía de ferrocarril entre Sevilla y Alcalá de Guadaíra, paralelo a las tapias de la factoría de Hytasa. Tras su desmantelamiento, este borde se convertirá en la trasera de la barriada Paz y Amistad.

- La línea del muro de defensa contra las avenidas del río Guadaíra (afluente del Guadalquivir) fijaba el límite por el sur, incluyendo los terrenos pertenecientes al Club Pineda. Tras el desvío del cauce, la carretera de Su Eminencia y el Parque del Guadaíra, que pretende servir de corredor verde metropolitano, son los espacios que caracterizan este frente.

- Por el oeste, la línea de ferrocarril Sevilla-Cádiz separa de manera contundente de otros barrios del Distrito Sur. Con sus muros adyacentes, se extiende, de norte a sur, entre el viaducto Marqués de Luca de Tena y la carretera de Su Eminencia.

Figura 1. Emplazamiento urbano y límites originales de Polígono Sur.

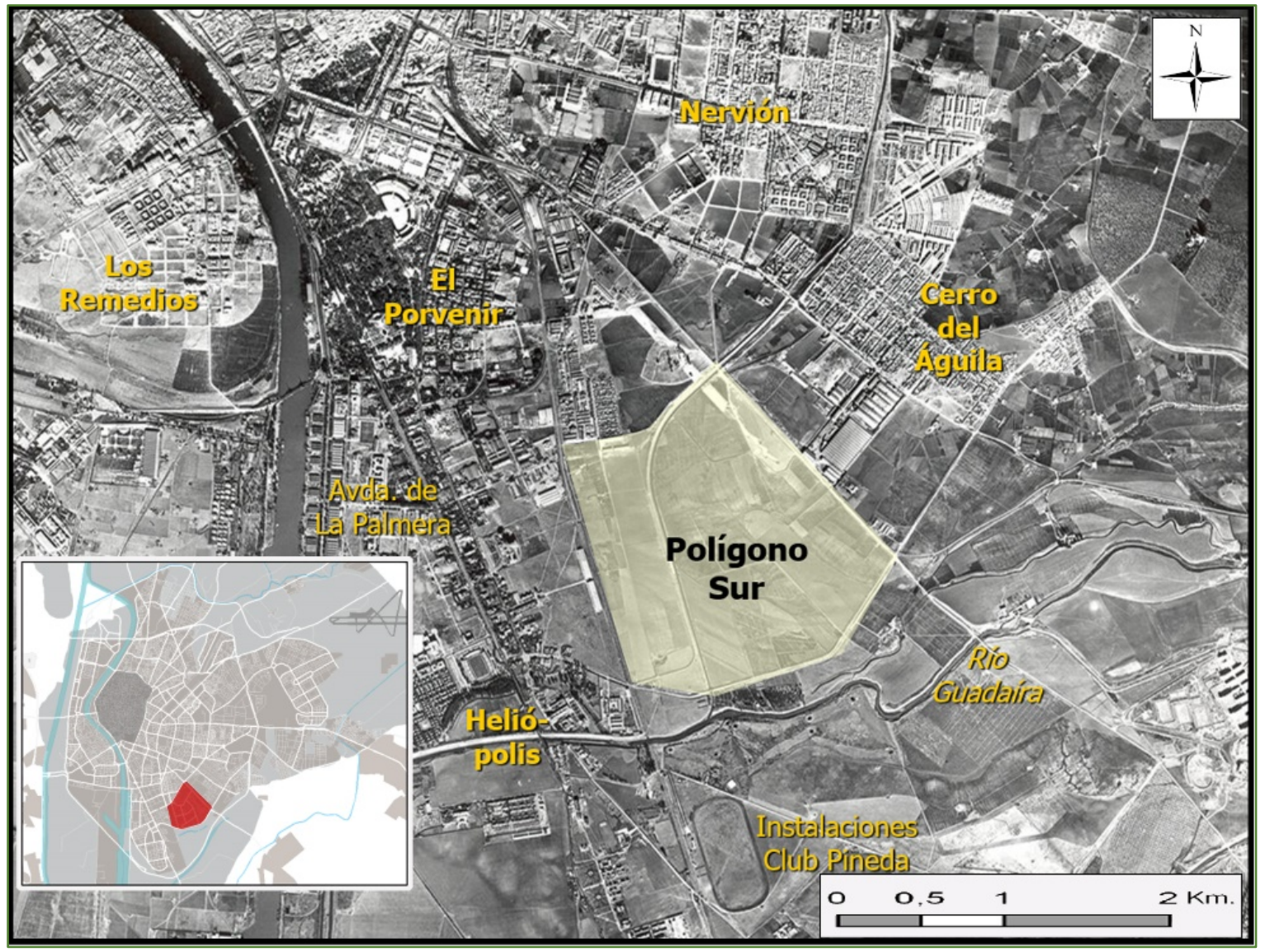

Fuente: Elaboración propia a partir de la fotografía aérea de 1956 (Vuelo Americano). Provincia de Sevilla, (H.M.N. 984). 
Este emplazamiento ayuda a reconocer los elementos territoriales originarios de este ámbito: terrenos bajos y aislados en el extremo meridional de una ciudad que ya manifestaba su expansión a partir de ensanches burgueses consolidados, como el del Porvenir, o con un desarrollo incipiente, como Nervión y Los Remedios. Otros núcleos de origen humilde, levantados mediante autoconstrucción, proliferaban desde décadas atrás por la periferia, como es el caso del Cerro del Águila.

En definitiva, la unidad urbanística que será conocida como Polígono Sur, se conforma a partir de las promociones públicas de viviendas que se ubicarán en este amplio solar, de 146 hectáreas. Desde su colmatación residencial, las barriadas que lo componen son Nuestra Señora de La Oliva (o La Oliva), Las Letanías, Murillo, Antonio Machado, Martínez Montañés y Paz y Amistad. El número total de viviendas es de 8.834 lo que, a comienzos de los años 80, pudo suponer una población aproximada de 44.000 habitantes si se aplica una ratio genérica de 5 personas por vivienda. No obstante, es muy difícil determinar la población real de la totalidad del barrio debido a la propia movilidad existente y a la irregularidad de muchas de las ocupaciones que se producen. En la actualidad (2020), según el Padrón Municipal de Habitantes (Ayuntamiento de Sevilla - Servicio de Estadística, consulta realizada el 18 de junio de 2020) existe un total de 28.735 habitantes distribuidos del siguiente modo: La Oliva (5.395), Las Letanías (3.669), unidad que definen Murillo, Antonio Machado y Martínez Montañés, denominada específicamente Polígono Sur (16.699), Paz y Amistad (2.972).

\section{Síntesis metodológica. Dos aproximaciones a una misma realidad marginal}

Distintos trabajos elaborados recientemente a nivel internacional (Tammaru et al. 2016; Nijman y Wei 2020) inciden, con una perspectiva geográfica y cuantitativa, en la agudización que están experimentando las desigualdades urbanas en el mundo. En una línea semejante, la aproximación que en primer lugar se ofrece en este texto está basada en la síntesis de análisis efectuados por varios trabajos que, mediante técnicas multivariantes, vienen a caracterizar los niveles de desigualdad que sufren las áreas urbanas que se delimitan, pertenecientes a ciudades españolas, andaluzas y de la propia Sevilla. Si bien hay importantes divergencias entre ellos (variables seleccionadas, unidades espaciales de referencia, tratamientos geoestadísticos, ámbito geográfico de aplicación...) en la mayor parte de los casos las fuentes utilizadas son los censos oficiales de población y viviendas que realiza el Instituto Nacional de Estadística, concretamente los de 1991, 2001 y 2011. A partir de ello, se puede establecer tanto una mirada sincrónica, donde la descripción se centra en la comparación simultánea, como un punto de vista diacrónico, en el que se atiende a los cambios que experimentan los indicadores más significativos a lo largo de los últimos treinta años.

En segundo lugar, profundizamos en el abordaje de la cuestión a través de una óptica más compleja y cualitativa; situamos la historia de Polígono Sur en el marco de los condicionantes que muestran su influencia desde distintas escalas territoriales y entornos políticos y económicos, y en el contexto de los múltiples factores -exógenos, relacionales y endógenos- que intervienen a nivel local y en su propia dinámica interna. En este sentido, partimos de la idea de que los fenómenos y procesos de marcos geopolíticos superiores 
influyen notablemente en la realidad de los ámbitos territoriales que se circunscriben en ellos: cada vez más, en el actual contexto globalizador "la ciudad parece integrar todo el mundo (su diversidad y desigualdad) dentro de su propio espacio" (Soja 2008, 224).

Figura 2. Encuadre general multiescalar e interrelaciones urbs-civitas-polis en el contexto del barrio.

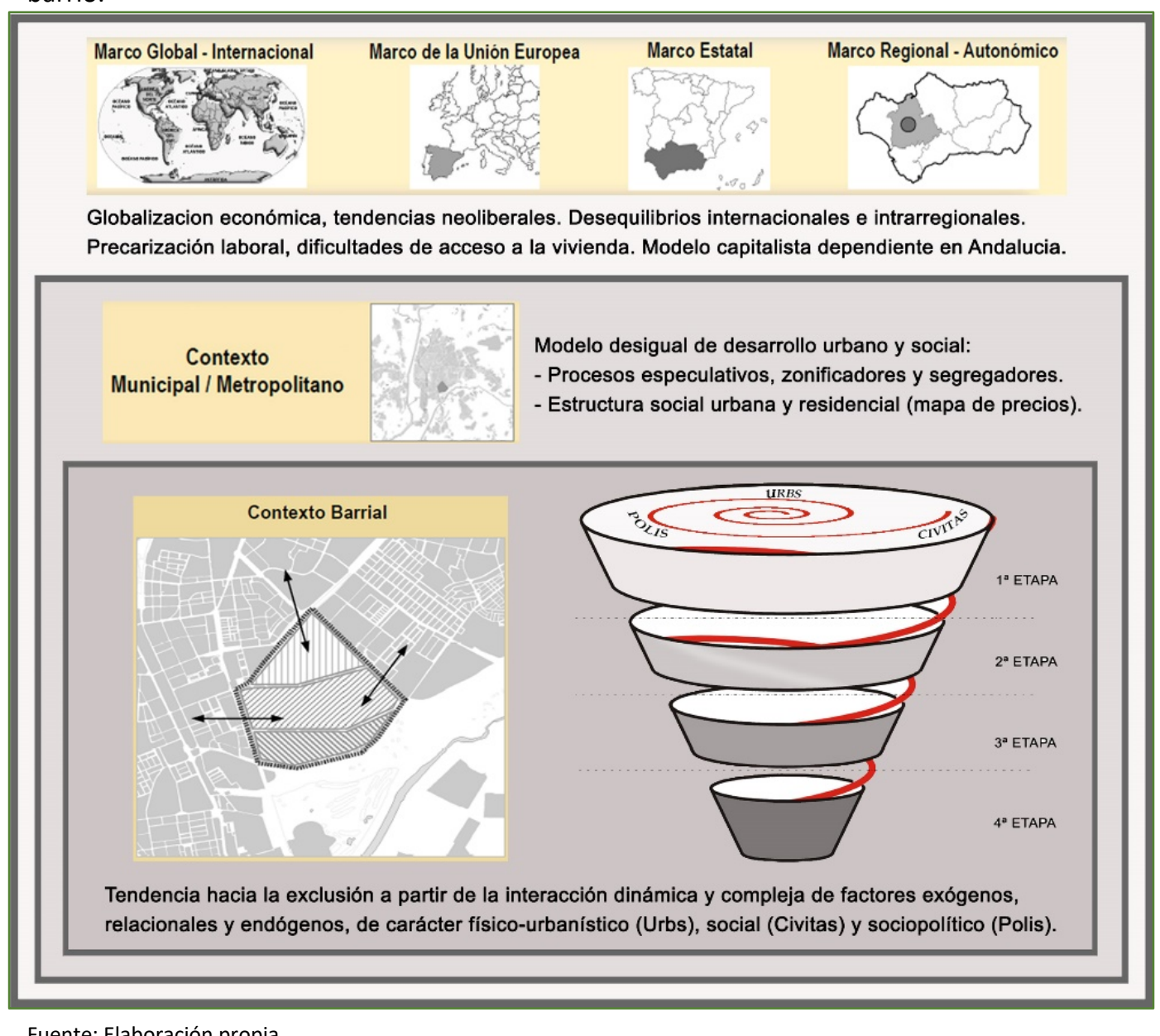

En el marco socioeconómico y territorial de Andalucía, podemos observar los caracteres propios de un modelo capitalista en general dependiente (Arenas 2016), mientras que a nivel local, municipal y metropolitano, la orientación de la política urbana y los fenómenos que se vinculan con el funcionamiento del mercado de la vivienda, las operaciones especulativas y posibilidades residenciales (planificación y zonificación social, renovaciones y recualificaciones, gentrificación y turistificación, deterioro y marginación...) manifiestan mecanismos determinantes en la consolidación de la segregación urbana. Estos, siguiendo interpretaciones marxianas, pueden explicarse en gran medida por el modo en que el capitalismo produce un paisaje geográfico adecuado para su propia dinámica de acumulación (Harvey 1977). De manera complementaria y combinada con el criterio multiescalar anterior, el análisis se organiza a partir de las tres categorías conceptuales ya descritas (urbs, civitas y polis) (Capel 2003), que tratan de aprehender las múltiples facetas de la realidad urbana. 
Por otro lado, profundizando aquí en los planteamientos de nuestro trabajo doctoral (Torres 2013), ambas aproximaciones, cuantitativa y comparada, cualitativa y compleja, así como sus criterios metodológicos y categorías conceptuales, se integran para ofrecer una representación esquemática y metafórica de la trayectoria histórica que ha experimentado el barrio, desde su origen hasta la actualidad. Las diferentes etapas que se distinguen (19641981, 1981-1992, 1992-2008 y 2008-2020) contemplan el modo en que se producen, según contextos y tendencias, las relaciones e interrelaciones (dialécticas) entre las tres dimensiones señaladas. Una espiral, que en función de ello se perfila verticalmente en forma de embudo, expresa gráficamente esta interpretación (figura 2).

\section{Las duras cifras de Polígono Sur. Aproximación cuantitativa}

\section{La oportunidad del análisis multivariante a partir de la estadística censal, 1991 y 2001}

La fuente del Censo de Población y Viviendas de 1991 facilitó una importante información estadística -desagregada por primera vez en secciones censales- que permitió la elaboración de múltiples análisis urbanos fundamentados en el tratamiento de variables muy distintas, concernientes a aspectos demográficos, socioeconómicos y propiamente habitacionales que, partiendo de indicadores específicos, podían integrarse en índices sintéticos expresivos de los desequilibrios espaciales existentes en la ciudad. El Índice de Desigualdad Urbana Municipal, presentado en un informe del Ministerio de Fomento (Arias 2000), es aplicado en todos los municipios españoles mayores de 50.000 habitantes bajo una clasificación tipológica basada en la forma de crecimiento urbano.

Teniendo en cuenta los indicadores señalados para 1991, la comparación de las principales áreas urbanas-metropolitanas españolas (por encima del millón de habitantes) indica que las desventajas que mayormente experimentan los barrios desfavorecidos de Sevilla guardan relación con el factor sociolaboral; la tasa de paro general y juvenil que muestran las secciones correspondientes, 33,5\% y 50,3\% respectivamente, son muy superiores a las de Madrid, Barcelona, Valencia y Bilbao. Así mismo, la contextualización de esta desigualdad urbana a nivel nacional manifiesta la intensidad de los desequilibrios interregionales: mientras que en Sevilla la población desfavorecida alcanza el 47\%, en las otras áreas metropolitanas oscila entre el 3,2\% de Bilbao y el 7,5\% de Valencia (ob. cit., 45 y 70).

Esta metodología descrita es asimilada y aplicada en detalle en el trabajo de Jaraíz y Cañestro para la Mesa 4 del Prediagnóstico del Plan General de 2006 (Jaraíz y Cañestro 2006). El mapa de la desigualdad elaborado representa la distribución de áreas vulnerables (desventajas por encima de la media) y barrios desfavorecidos en distinto grado a partir del umbral que establecen las desviaciones típicas. De este modo, los barrios desfavorecidos se extienden principalmente en la periferia que definen los polígonos de viviendas sociales de los años 60 y 70; hacemos referencia a Polígono Norte, Tres Barrios-Amate, Polígono San Pablo y Polígono Sur. Dentro del municipio, los valores más extremos solo se observan en este último barrio, lo que subraya, a principios de la década de los 90, la gravedad de las concentraciones de pobreza y vulnerabilidad social que en él se producen. 
Al poco tiempo de la publicación de los trabajos anteriores, la divulgación de los resultados del Censo de 2001 dio la oportunidad de continuar realizando análisis con estas características, pudiendo aplicar observaciones diacrónicas sobre la evolución de los datos. En nuestro trabajo (Torres y García 2011; Torres 2013), damos continuidad al Índice de Desigualdad Urbana Municipal. En él se comparten los criterios expuestos en las investigaciones de Arias (2000), de Jaraíz y Cañestro (2006), en el Atlas de la Vulnerabilidad Urbana en España 2001 y $2011^{2}$ (Ministerio de Fomento 2015) y por el estudio de Egea et al. (2008), si bien en estas dos últimas obras se aplican tratamientos más complejos.

A partir de la definición sintética de los tres indicadores empleados (tasa de paro, porcentaje de población sin estudios y porcentaje de viviendas en estado deficiente), conseguida mediante su normalización, integración y tipificación, la clasificación se establece nuevamente en base a la dispersión (una o dos desviaciones típicas) de los valores respecto a la media. En nuestro análisis, la barriada La Oliva presenta una situación similar a la de otros sectores urbanos plenamente integrados o "no vulnerables", casi todas las secciones de Las Letanías, junto a las de Paz y Amistad, reflejan desventajas relativas, mientras que barrios como Murillo, Martínez Montañés y Antonio Machado acogen las poblaciones más desfavorecidas, en un nivel grave y muy grave. Estas situaciones extremas solo son apreciables en otros tres sectores urbanos de Sevilla, en Tres Barrios-Amate, Su Eminencia y Torreblanca, aunque no con la misma extensión y profundidad. Otros indicadores, elaborados gracias a esta misma fuente del Censo, son por sí solos reveladores de la notable desigualdad que sufre esta área de la ciudad: el reducido número de personas con estudios superiores y la escasa cualificación laboral son alarmantes en algunos vecindarios de Polígono Sur.

\section{La evolución 2001-2011. Análisis intercensal y otros indicadores específicos}

Tal como se explica en la obra de Egea y Nieto (2015) (derivada del proyecto disponible en http://condicionesdehabitabilidad.com/) el Censo de 2011 presenta importantes condicionantes y puede considerarse menos fiable en sus resultados finales, especialmente en la escala inframunicipal (ob. cit., 49). No obstante, el tratamiento estadístico llevado a cabo y la agrupación de los datos en unidades territoriales de referencia (UTR) que agrupan un cierto número de secciones censales contiguas, sí consigue mayor fiabilidad, ya que no solo permite la obtención de los indicadores diferenciados entre áreas, también facilita una aproximación diacrónica (2001-2011) que ayuda a comprender la tendencia de las manifestaciones de desventaja y su posible relación con determinados factores.

Centrándonos en la lectura de los mapas correspondientes a los dos indicadores finales, el Indicador de Desfavorecimiento (2011), destaca el nivel muy alto de cuatro UTR en Sevilla: Polígono Sur, Amate-Ciudad Jardín, Tres Barrios y San Pablo. En relación con el

\footnotetext{
2 En dicho Atlas (http://atlasvulnerabilidadurbana.fomento.es/) la esperada comparación diacrónica (20012011) no resulta plenamente convincente. Mientras que los resultados de 2001 muestran su sintonía con otros trabajos efectuados, la representación de los correspondientes a 2011 revelan la incongruencia de estos en algunas secciones determinadas, lo que remite a los problemas procedimentales del último censo y a sus dificultades en el tratamiento estadístico.
} 
Indicador de Déficit Habitacional, la desigualdad urbana cartografiada también sitúa Polígono Sur entre los casos con mayores desventajas. Con un nivel muy alto aparecen también algunas áreas de la periferia este y norte en Sevilla; se trata principalmente de barrios obreros de baja calidad constructiva surgidos en las décadas de los sesenta y setenta del siglo pasado y que no han sido suficientemente atendidos a nivel urbanístico y arquitectónico.

Esta desigualdad intraurbana fundamentada en aspectos socioeconómicos, laborales y formativos, así como en la concentración de situaciones de vulnerabilidad social, resulta muy significativa en un marco temporal en el que, en términos generales, se ha producido una leve mejora de los indicadores utilizados. Si bien años antes tiene lugar la Gran Recesión, los efectos de esta crisis se hacen notar, especialmente, a partir de 2013, cuando la tasa de desempleo alcanza sus mayores cotas. En 2011 por tanto, a raíz de la reconfiguración urbana y los procesos socio-residenciales que acontecen con el boom inmobiliario de la década anterior (expansión por nuevos desarrollos, renovación de algunos sectores, movilidades...), las circunstancias sociales desveladas mediante métodos cuantitativos como este denotan todavía la mejora relativa apuntada.

En el área de Polígono Sur (según su delimitación general) llama la atención la mitigación de desventajas en La Oliva y Las Letanías, fenómeno probablemente vinculado con una cierta revitalización urbana que se produce durante la década anterior, cuando tiene lugar la construcción de los bloques Giralda (que terminarán acogiendo la Residencia Flora Tristán), el acondicionamiento del bulevar de la Avenida de La Paz y del Parque José Celestino Mutis y la instalación de una gran superficie comercial en las inmediaciones. Otros barrios de la ciudad, como Polígono Norte o Torreblanca, también parecen mejorar por factores semejantes.

Desde esta perspectiva evolutiva intercensal y reparando en el carácter y alcance de indicadores concretos, hay que distinguir y destacar los casos de Polígono Sur y Tres Barrios. Mientras que en el primero algunos indicadores relacionados con el empleo muestran una trayectoria menos negativa o incluso una cierta mejora, en Tres Barrios sin embargo el empeoramiento se refleja en todas las facetas consideradas, probablemente a causa de la agudización de los efectos que provoca la crisis económica. No solo muestra los peores datos a nivel formativo, socioeconómico y laboral, también acusa la antigüedad y precariedad de las viviendas y el envejecimiento de su población. En este sentido, es posible que en Polígono Sur hayan tenido una influencia positiva los programas de formación e inserción sociolaboral y otras medidas del Plan Integral.

En los últimos años, ya con cierta distancia de la referencia censal de 2011, fuente oficial no exenta de las limitaciones señaladas, las informaciones con este carácter han aparecido a raíz de estadísticas recientes basadas en variables demográficas y socioeconómicas. Las fuentes en este caso se vinculan con iniciativas apoyadas o desarrolladas por el Instituto Nacional de Estadística, como los Indicadores Urbanos del proyecto europeo Urban Audit (INE 2020), en el que se recopila información de interés para 
comparar la calidad de vida en las principales ciudades europeas ${ }^{3}$, y el ADRH o Atlas de Distribución de Renta de los Hogares (INE 2019), operación censal con carácter experimental en la que se combina información básica sociodemográfica con datos tributarios, fundamentalmente de la AEAT.

Bajo estas consideraciones, distintos indicadores de 2017 descriptivos del nivel de renta, como la renta neta media anual de los hogares, señalan que las áreas más deprimidas de Sevilla son las de Tres Barrios-Amate (13.849 €), las barriadas Murillo, Martínez Montañés y Antonio Machado, de Polígono Sur (15.252 €), Torreblanca (17.291 €) y el subdistrito que integra Las Letanías y La Oliva (18.937 €), también en Polígono Sur. De acuerdo con ello, Tres Barrios, con una renta inferior al 50\% de la media municipal, constituye el barrio más pobre de la ciudad e incluso de todo el país. Así mismo, tanto la renta neta media por habitante como por unidad de consumo, igualmente contempladas en este proyecto, sitúan Polígono Sur en la posición más negativa.

Por último, según los datos ofrecidos por el ADRH, con fuentes estadísticas de 2018 que se expresan en el máximo nivel de desagregación territorial, dos secciones censales del Polígono Sur, coincidentes con un sector de Murillo y algunos de los bloques de Martínez Montañés, dentro de sus 624 Viviendas, presentan rentas medias per cápita inferiores a $2.897 €$, umbral mínimo establecido en la clasificación a causa del respeto al secreto estadístico. Estas dos secciones junto a otras seis (de estos mismos barrios y de Las Letanías) cuyas rentas se sitúan entre los 3.000 y $4.000 €$, se encuentran en el rango del 1\% más pobre de Andalucía y de toda España.

\section{Un declive en espiral. Aproximación cualitativa}

\section{1a. Etapa, 1964-1981. La construcción de un "contenedor de pobres"}

En las décadas de los sesenta y setenta, la llegada a Sevilla de inmigrantes procedentes del éxodo rural resulta más intensa que nunca y debe ser entendida como parte de un contexto migratorio internacional, además de interior, que iría dando lugar a una redistribución importante de la población española. Esta fuerte inmigración, unida al deterioro del patrimonio habitacional existente en el casco urbano sevillano y a la cantidad de infraviviendas y chabolas que existen en la periferia, conlleva la agudización de las necesidades de vivienda y la activación de un sector de la construcción que vive unos momentos expansivos de crecimiento urbano e industrial. A partir de este escenario general, se produce una zonificación social derivada de las operaciones especulativas en la ciudad histórica y de las actuaciones que se efectúan en la periferia, muy influenciadas por el carácter, destino y localización de las promociones públicas y privadas.

Tal como plantea Marín de Terán, el urbanismo que pone en práctica el PGOU de 1963 “se caracteriza por un intenso desarrollo irreflexivo en el que, únicamente, se atiende a la

3 En el proyecto Urban Audit, la desagregación territorial a nivel submunicipal define los denominados subdistritos de la ciudad (SCD), ámbitos en los que se agregan secciones censales que llegan a sumar entre 5.000 y 40.000 habitantes. En función de este criterio, algunos SCD integran áreas urbanas muy heterogéneas, tanto a nivel urbanístico como social, hecho que implica el enmascaramiento de las situaciones agudas que presentarían determinados barrios si la delimitación se ajustara a su propio espacio urbano. 
rápida consecución de ciertas metas cuantitativas y no se consideran los graves problemas que a la larga pueden acarrear las improvisaciones del momento" [...] "Bajo una aparente neutralidad técnica, no hace otra cosa que materializar un proceso político-económico por medio del cual ciertos sectores del capital se hacen cargo definitivamente de la ciudad" (1980, 103-104). En este contexto, el crecimiento desordenado que implica la yuxtaposición de actuaciones autónomas, acentúa la segregación espacial de las funciones urbanas.

La dicotomía que representa el esquema territorial "Centro-Periferia", característico tradicionalmente en la ciudad por la diferenciación Sur-Norte del casco antiguo, se reproduce en este periodo con otro desarrollo espacial, sobre todo a partir de la expansión hacia el este y hacia el sur. En los polígonos de vivienda social que se crean van a tener lugar procesos de difícil hibridación entre poblaciones empobrecidas de distintos orígenes: inmigrantes rurales, desahuciadas del centro histórico, chabolistas de poblados repartidos por el municipio, familias de etnia gitana procedentes de corralas del casco y arrabales históricos (como Triana, Macarena o San Bernardo) o realojadas desde Unidades Vecinales de Absorción o desde refugios provisionales ${ }^{4}$.

La progresiva colmatación residencial del área urbana que se define como Polígono Sur se inicia con el núcleo provisional de las Casitas Bajas, 1.064 viviendas prefabricadas instaladas por la Secretaría Provincial de Vivienda y Refugios (S.V.R.) en las que se realojan familias con muy escasos recursos. El Cuadro 1 recopila sintéticamente los diferentes proyectos urbanísticos que se sucedieron, así como sus características básicas: construcción, promoción, dimensión y composición social.

A partir de 1970, la expansión del barrio se produce con la creación de las barriadas de Ntra. Sra. de La Oliva y de Las Letanías. La primera, a diferencia de las barriadas vecinas, auspiciadas por organismos públicos como el Instituto Nacional de la Vivienda (I.N.V.), se levanta en virtud de una Asociación Cooperativa de promoción municipal, lo que le otorgará una morfología urbana particular y una condición socioeconómica y cultural comparativamente aventajada. A Las Letanías se desplazan algunas familias de las Casitas Bajas mientras que, en el asentamiento original de estas, se vuelve a realojar personas de diversos refugios o que han sufrido desahucios en el centro de la ciudad. Se trata de una dinámica que se reproduce cíclicamente a medida que se crean nuevas barriadas.

En 1976 se construyen "Las Tres Mil Viviendas", barriada bautizada oficialmente con el nombre de "Murillo". Llega a ella una población proveniente de distintos suburbios e infraviviendas. Se generó un colectivo vecinal desarraigado y de aluvión que adquirió un alto índice de marginalidad, la conflictividad social aumentó entonces mucho unida al tráfico y consumo de drogas. Pese a ello, fue destacable en este contexto la labor de distintas asociaciones y de algunos párrocos salesianos.

A finales de los setenta se crean las barriadas de Antonio Machado y Martínez Montañés, donde se alojan familias que se acogen al Programa de Cambios municipal y aquéllas que aún permanecían en las Casitas Bajas, precisamente las que no tenían recursos suficientes para haber abandonado el núcleo con anterioridad. Tal actuación representó la

4 Construidos a iniciativa de la Secretaría de Viviendas y Refugios, consistían en grupos de viviendas prefabricadas o edificaciones que eran adaptadas para cubrir aquella necesidad perentoria. 
consolidación definitiva del barrio como una de las zonas más desfavorecidas y complejas de la ciudad. Como apuntábamos anteriormente, ello condena a su población más comprometida a tener que reinventar continuamente procesos regeneradores ante las sucesivas y recurrentes avalanchas de grupos humanos cada vez más marginales (Camacho 1996).

\begin{tabular}{|c|c|c|c|c|}
\hline $\begin{array}{l}\text { Proyectos } \\
\text { urbanísticos / } \\
\text { Barriadas }\end{array}$ & $\begin{array}{l}\text { Año de } \\
\text { construc- } \\
\text { ción }\end{array}$ & $\begin{array}{c}\text { Organismo } \\
\text { promotor }^{5 /} \\
\text { Carácter viviendas }\end{array}$ & $\begin{array}{l}\text { Número de } \\
\text { viviendas / } \mathrm{N}^{\mathrm{o}} \text {. } \\
\text { aprox. de } \\
\text { habitantes }\end{array}$ & Origen y composición social \\
\hline $\begin{array}{l}\text { Unidad Vecinal } \\
\text { de Absorción }{ }^{6}\end{array}$ & 1964 & $\begin{array}{l}\text { S.V.R./ } \\
\text { Alojamientos } \\
\text { provisionales }\end{array}$ & $1.008 / 6.000$ & $\begin{array}{l}\text { Diversos orígenes y condiciones } \\
\text { dentro del contexto de precariedad. } \\
\text { Hogares afectados por inundaciones. }\end{array}$ \\
\hline $\begin{array}{l}\text { Nuestra Señora } \\
\text { de La Oliva }\end{array}$ & 1970 & $\begin{array}{l}\text { P.M.V./ } \\
\text { Protección oficial }\end{array}$ & $1.250 / 8.000$ & $\begin{array}{l}\text { De clase media-baja, pero con cierta } \\
\text { estabilidad laboral y capacidad } \\
\text { económica. }\end{array}$ \\
\hline Las Letanías & 1970 & $\begin{array}{l}\text { I.N.V. - O.S.H.A. } \\
\text { / Viviendas } \\
\text { sociales }\end{array}$ & $1.500 / 7.000$ & $\begin{array}{l}\text { De diversos refugios, en su mayor } \\
\text { parte de San Pablo. }\end{array}$ \\
\hline Murillo & 1976 & $\begin{array}{l}\text { I.N.V. - O.S.H.A. } \\
\text { / Viviendas } \\
\text { sociales }\end{array}$ & $3.000 / 15.000$ & $\begin{array}{l}\text { De asentamientos ilegales, núcleos } \\
\text { chabolistas y refugios, entre ellos La } \\
\text { Corchuela. }\end{array}$ \\
\hline $\begin{array}{l}\text { Antonio } \\
\text { Machado }\end{array}$ & 1978 & $\begin{array}{l}\text { I.N.V. - O.S.H.A. } \\
\text { / Viviendas } \\
\text { sociales }\end{array}$ & $760 / 4.000$ & $\begin{array}{l}\text { De refugios y desahuciadas del } \\
\text { centro y arrabales históricos. }\end{array}$ \\
\hline $\begin{array}{l}\text { Martínez } \\
\text { Montañés }\end{array}$ & 1978 & $\begin{array}{l}\text { I.N.V. - O.S.H.A. } \\
\text { / Viviendas } \\
\text { sociales }\end{array}$ & $1.504 / 6.000$ & $\begin{array}{l}\text { De refugios, como el de la propia } \\
\text { U.V.A. de La Paz, prácticamente } \\
\text { convertido en núcleo de chabolas. } \\
\text { También desahuciadas. }\end{array}$ \\
\hline Paz y Amistad & 1980 & $\begin{array}{l}\text { I.N.V. - O.S.H.A. } \\
\text { / Viviendas } \\
\text { sociales }\end{array}$ & $820 / 4.000$ & $\begin{array}{l}\text { Familias acogidas en refugios, como } \\
\text { el de la propia U.V.A. de La Paz. }\end{array}$ \\
\hline
\end{tabular}

Cuadro 1. Proyectos urbanísticos o barriadas que conformaron el conjunto de Polígono Sur.

Caracteres básicos.

Fuente: Elaboración propia a partir de Camacho (1996).

Paradójicamente, las viviendas de Martínez Montañés, pese a ser de las más recientes y contar con superficies aceptables y con instalaciones y acabados de mayor calidad, terminan constituyendo el núcleo más degradado. Varias interpretaciones, complementarias, pueden desvelar las claves de este hecho:

La caótica gestión inicial de los realojos efectuada por la Administración, más preocupada por erradicar rápidamente los refugios y chabolas que por facilitar la integración en el nuevo escenario (Vorauer 2011, 115).

5 Detallamos el significado de las siglas: S.V.R. (Secretaría de Viviendas y Refugios), P.M.V. (Patronato Municipal de la Vivienda), I.N.V. (Instituto Nacional de la Vivienda), O.S.H.A. (Obra Sindical del Hogar y Arquitectura).

6 El refugio de las U.V.A. se va desmantelando a medida que se construyen estas barriadas, trasladándose a ellas la población de este núcleo original. 
Las dificultades de adaptación a un tipo de hábitat totalmente distinto al original, probablemente más difícil en grupos de etnia gitana con experiencia chabolista o con hábitos domésticos no satisfechos por las tipologías de vivienda dominantes en la cultura urbanística moderna (ob. cit.).

El propio desarraigo y el choque relacional que se produce con el nuevo entorno y entre poblaciones vulnerables de tan dispares procedencias (Coca 2001).

Obviamente, junto a lo anterior, hay que considerar el descontrol de la ocupación y usos de estas viviendas por parte de las administraciones públicas responsables, primero el Estado y luego la Junta de Andalucía, un hecho crucial para la progresiva degradación de la zona.

Finalmente, en 1981, tras el derribo definitivo de las Casitas Bajas, se entregan los dos núcleos de viviendas que se ubican al otro lado de la avenida de La Paz, es decir, las 400 y 420, que corresponden a la barriada Paz y Amistad. La composición social, si bien es similar a la de los proyectos anteriores, mostrará un nivel de desventajas socioeconómicas menos acusado.

Las expectativas respecto a la revalorización del suelo se producen durante este periodo en muchas partes de la ciudad. Sin embargo, el único enclave que no suscita suficiente interés para la iniciativa privada y que, por este motivo, quedará relegado a la intervención de la promoción pública, será el de los periféricos y aislados terrenos del Polígono Sur. Se trata de una evidente zonificación social orientada por los intereses del mercado de la vivienda. Es este el modo en que termina de configurarse un espacio que, a cambio de conseguir ventajas económicas y de seguridad para el resto del municipio, termina convertido en un verdadero contenedor de pobres.

A partir de los orígenes comentados, con el paso de los años las distintas barriadas van a experimentar tendencias divergentes en relación a su deterioro y vulnerabilidad social. Mientras que La Oliva y el entorno de la Avenida de La Paz, espacios mejor comunicados e integrados en la trama urbana, van a mantener unas condiciones de vida -reflejadas en la conservación del hábitat- similares a la de otros barrios no desfavorecidos de Sevilla, en los sectores más deprimidos, cercanos a la carretera de Su Eminencia, los problemas sociales serán acuciantes y se manifestarán en muchos sentidos. Desde la década de los noventa, el tráfico de drogas y la inseguridad, entre otros aspectos, se expanden desde Martínez Montañés hacia los bloques de barrios limítrofes, especialmente de Murillo y Las Letanías. Este fenómeno, que representa una clara territorialidad de la exclusión en el barrio, se interpreta desde el plano de la percepción subjetiva cuando se realiza un recorrido desde el lado norte, en el entorno de La Oliva, hasta el límite meridional. El plano de la figura 3, considerado de interés en los diagnósticos y memorias del Plan Integral (Comisionado para el Polígono Sur 2013, 34) califica los sectores que pueden distinguirse de acuerdo con esta interpretación. 
Figura 3. Percepción de la desigualdad socio-espacial.

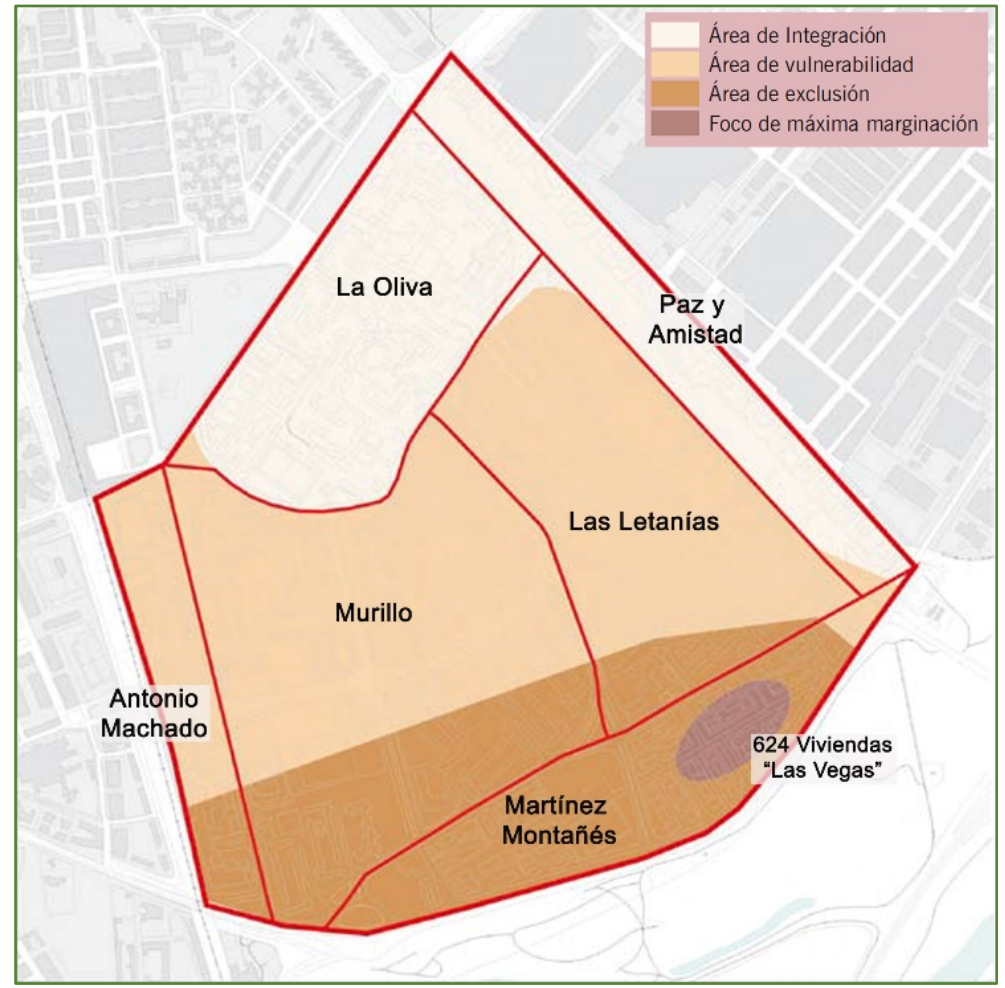

Fuente: Elaboración propia.

\section{2a. Etapa, 1981-1992. El abandono de la periferia}

En Andalucía, con una economía frágil, tiene impacto a finales de los setenta lo que se conoció a nivel mundial como la "crisis del petróleo", inicio de una nueva etapa del sistema de producción y de los mercados internacionales, que puso al descubierto, especialmente en esta región, la debilidad del Estado del Bienestar (Carmona 2008). El paro y la precariedad del empleo indujeron importantes procesos de polarización social, así como de precarización frente a determinadas tendencias de aburguesamiento. A nivel territorial, como ya se ha indicado, el mercado de la vivienda y los nuevos modelos urbanísticos se manifiestan en situaciones de fragmentación y dualización social.

Por otra parte, desde mediados de los ochenta, Sevilla sería beneficiada por su papel como capital autonómica de Andalucía. Ello, unido a la tendencia algo más favorable de la economía, junto a la decisión de celebrar la exposición universal de 1992, abrió un proceso de fuerte transformación urbana. Así, en base a las determinaciones del PGOU de 1987, el lustro que precede a su celebración significó el desarrollo de numerosas infraestructuras públicas que mejoraron considerablemente las comunicaciones, equipamientos y espacios culturales. El resultado fue la conformación de una ciudad nueva en la que se concentraron, en pocos años, recursos que solventaron carencias que había mostrado su desarrollo urbano y que marcarán este periodo y la historia reciente de la ciudad (Guerrero y López 2012, 67).

A pesar de lo anterior, las obras públicas que se realizaron repercutieron con consecuencias contradictorias según las distintas áreas de la ciudad. Mientras algunas 
provocaron una notable recualificación urbana, otras no contribuyeron del mismo modo y derivaron en una segregación funcional, sobre todo a nivel de estatus social, que las sucesivas reformas ejecutadas no eliminarían: por un lado, la ronda del Tamarguillo, con bulevar anejo, va a delimitar sectores muy diferenciados desde el punto de vista socioeconómico; debido a su diseño y uso se convierte más en un espacio barrera que en un lugar para el esparcimiento y encuentro. Por otro lado, hay que señalar el mantenimiento en superficie del ramal ferroviario de la línea Sevilla-Cádiz.

Desde el punto de vista general de la urbs, en los años ochenta, en los que se hereda la zonificación generada por la planificación y especulación de las dos décadas anteriores, se mantienen las tendencias polarizadoras a partir de dos hechos: la reubicación de las clases medias en nuevos barrios de la ciudad y las dificultades que, ante la escasa cantidad de viviendas protegidas que se construyen, tienen las familias más pobres para acceder a ellas. Se deben contemplar además otras circunstancias en este sentido; a lo largo de estos años se va afianzando el proceso de metropolización, y parte de la población de clase media y mediaalta traslada su residencia a otros municipios vecinos, generándose así una segregación socioespacial, con estilos residenciales muy diferenciados, en el marco de esta escala territorial. Así mismo, la concentración de determinadas funciones en el casco histórico, da lugar a que se refuercen en él dinámicas gentrificadoras.

En el seno de Polígono Sur es muy significativo el modo en que se efectúa y percibe el soterramiento del ferrocarril Sevilla-Cádiz, mantenido en superficie a partir del extremo sur de la renovada avenida Ramón Carande, en el entorno del hospital Virgen del Rocío. Por otro lado, a pesar del grado de marginación ya alcanzado, se malogra la oportunidad de un ambicioso Plan Especial de Mejora Urbana, tal como se tenía previsto, interviniéndose solo a partir de múltiples operaciones de reurbanización que, por su focalización y carácter sectorial no van a representar grandes cambios.

Desde el punto de vista social (civitas), la crisis económica y el desempleo consecuente tuvieron especial impacto en sus barriadas, donde la inestabilidad viene a subrayar las inercias que acentúan la vulnerabilidad. A partir de ello se vieron debilitadas algunas pautas de convivencia y aumentaron las conductas marginales y disputas en los vecindarios. Prolifera entonces una delincuencia menor, vinculada con robos $y$ atracos fundamentalmente, y actividades relacionadas con el narcotráfico, fenómenos que provocan una notable alarma social en la ciudad. En relación con esta cuestión, señala Luis Martín Valverde7, "el tráfico de drogas condiciona muchísimo todo el trabajo que se pueda llevar a cabo en estos barrios. Está presente en todos los ambientes y permea la forma de relacionarse los vecinos". Asevera, además: "mientras exista este comercio y esta fuente fácil de ingresos no se puede pensar en normalizar las condiciones de vida que aquí se dan; siempre habrá un buen grupo de personas, de familias, a las que no les interese la recuperación de la zona" (Martín 2020, 374-375). En este escenario, la cohesión interna queda muy erosionada y son los propios vecinos, con sus redes y organizaciones sociales, los

7 Sacerdote, miembro de las Juventudes Obreras Cristianas y fundador-presidente de la Asociación Entre Amigos (https://asociacionentreamigos.com/). Ha desarrollado una incesante labor en el barrio, sobre todo en relación con el absentismo escolar, el trabajo con familias y la integración sociolaboral. 
que debieron tomar la iniciativa para ofrecer respuestas solidarias a los problemas y necesidades colectivas (polis).

Al comienzo de este periodo, las movilizaciones ciudadanas, impulsadas por un creciente tejido asociativo favorecido por el nuevo marco democrático, reorientaron las protestas y demandas de años anteriores para centrarse en aspectos vinculados con las carencias de determinados equipamientos y servicios urbanos. Es entonces cuando cristalizan una serie de coordinadoras sectoriales que se agruparán en una Coordinadora General. Esto se convirtió en una fortaleza ciudadana muy valiosa, aunque se fue apagando a lo largo de la década de los ochenta. A esta decadencia contribuyó una Administración que fue amansando y cooptando las organizaciones sociales, forjando de este modo una evidente estructura clientelar. Con el tiempo, la desesperanza y la apatía se van instalando en el ánimo colectivo del barrio al no atisbarse síntomas o posibilidades reales de transformación.

\section{3a. Etapa, 1992-2008. De la imagen a la realidad. Las sombras del marketing urbano}

A lo largo de un periodo de 15 años, con notables cambios generales en términos económicos y sociales y tras el agotamiento del planeamiento de 1987 y del impulso modernizador generado por la Exposición de 1992, Sevilla carece de un modelo urbano que responda a las necesidades de la ciudad consolidada y que logre ordenar coherentemente su desarrollo ante los desmedidos crecimientos que conllevará el boom superespeculativo de la construcción. El PGOU de 2006, diseñado en el contexto de un gobierno municipal de PSOE e IU ("pacto de progreso por Sevilla") llegará demasiado tarde para rectificar y reequilibrar, mediante principios de sostenibilidad y participación, los procesos indicados.

Desde el punto de vista de los planteamientos urbanísticos generales, se afianza una orientación empresarial y estratégica de la política urbana. La celebración de la Expo'92 supuso la incorporación de Sevilla a las redes de la nueva economía posfordista y terciarizada y a las nuevas estrategias de promoción urbana, siendo definida como una "gran operación de marketing urbano" (Díaz 2010, 137) basada "en una política donde el binomio macroeventos-megaproyectos se concibe como principio de cambio y activación económica de la ciudad" (Guerrero y López 2012, 69). En este marco, los gobiernos municipales redirigen la atención hacia los sectores y espacios "de oportunidad" o "estratégicos", centrando sus miradas en los enclaves emergentes, simbólicos, atractivos..., con la intención de propiciar impulsos económicos y mediáticos de cierto alcance. Estos comportamientos de raíz economicista y sentido estético infieren nuevos significados de lo urbano y de las distintas áreas que componen la ciudad: mientras que unos espacios concentran las actividades de mayor relevancia y aparecen en muchos casos "sobrerrepresentados", otros quedan "invisibilizados" por la misma dicotomía del discurso. Así sucede por ejemplo con los barrios periféricos de la ciudad.

Como se ha podido ver en el tercer epígrafe de este texto (aproximación cuantitativa), las desigualdades urbanas que permiten evaluar los datos provenientes de los distintos censos (de 1991, 2001 y 2011) manifiestan una clara persistencia histórica de los sectores más empobrecidos, sobre todo los que se ubican en la periferia, ya sean antiguos barrios de autoconstrucción o promociones de vivienda pública de los 60 y 70. Entre ellos, con los 
peores indicadores, Polígono Sur. A lo largo de los noventa, este se consolida como el caso más representativo de la marginación social en Sevilla, su estigma se proyecta no solo en el ámbito de la aglomeración urbana sino a nivel andaluz y español.

Las actuaciones urbanísticas que vinieron a modernizar la ciudad tuvieron escaso efecto en el barrio, buena parte de los planes que se ponen en marcha desde las distintas administraciones tienen un carácter meramente sectorial y alcance puntual. Continúa pendiente el soterramiento del ferrocarril Sevilla-Cádiz, una de las fronteras urbanas más conspicuas dentro de toda la geografía española, con una dimensión física, económica, sociocultural, sociopolítica y simbólica que delimita paisajes urbanos y modus vivendi muy contrastados. La frontera que constituye el ferrocarril, así como el conjunto de límites que definen el área urbana de Polígono Sur, tienen su reflejo y afianzamiento en la configuración de un mapa de precios que dibuja una nítida geometría de la estructura social de la ciudad (Conde 2007); en definitiva, estamos ante otro mecanismo de segregación vinculado con la movilidad residencial y las dinámicas que consolidan las desigualdades urbanas.

El principal motivo del deterioro social del barrio puede vincularse especialmente con la evolución que ha ido experimentando su parte más extrema, junto a la carretera de $\mathrm{Su}$ Eminencia. Las 624 viviendas en Martínez Montañés (subzona conocida como "Las Vegas") se han ido convirtiendo en "un territorio sin ley" en el que establecen su jerarquía mafias y grupos delincuentes a raíz de los ya comentados traspasos ilegales de viviendas. Resulta de interés la distinción que realiza Vorauer entre las comunidades que se identifican según su interacción con la arquitectura y el espacio público: "los buenos", "los gitanos", "los drogodependientes" y "la mafia" (2011, 130-144). Ya en el nuevo siglo, cuando se plantea la intervención de la Oficina de Rehabilitación de Viviendas en Martínez Montañés, esta marginalidad comienza a extenderse por el resto del barrio, sobre todo a partir de familias concretas que se trasladan a Murillo o Las Letanías.

En un contexto general de decadencia de las tradicionales asociaciones de vecinos, en el que las prácticas subvencionistas de la Administración desarticulan en gran medida el tejido asociativo, aparecen plataformas como "Barrios en Lucha", que engloba diferentes iniciativas de la ciudad o "Nosotros también Somos Sevilla" (NtSS) dentro del propio Polígono Sur, herederas del movimiento vecinal clásico que se define bajo la fórmula de coaliciones contra la exclusión (Díaz 2010, 347). A raíz de determinados acontecimientos, expresivos del recurrente tratamiento del barrio como "patio trasero de la ciudad" (no soterramiento del ferrocarril, instalación de un "Punto Limpio", nuevo realojamiento de chabolistas...), esta plataforma se organiza para requerir una intervención decidida y coordinada por parte de una "Autoridad única". Es así como se conduce a la creación del Comisionado para el Polígono Sur y al nombramiento, en octubre de 2003, de D. Jesús Maeztu Gregorio de Tejada como representante del mismo ${ }^{8}$.

8 En los primeros años ejerce la labor de Comisionado este profesor de Derecho y actual Defensor del Pueblo Andaluz, nombrado según Decreto 303/2003. En 2013 es relevado en el cargo por la doctora en Psicología Dña. María de Mar González Rodríguez (Decreto 194/2013). Por último, en 2019 (Decreto 541/2019) se produce el nombramiento de D. Jaime Bretón Besnier, licenciado en Derecho, previamente Adjunto al Defensor del Pueblo. 
Al poco tiempo del nacimiento del Comisionado y en pleno proceso de redacción del Plan Integral, concretamente en 2004, tiene lugar un acontecimiento que entendemos clave, que va a profundizar nuevamente en las desventajas que ha sufrido el barrio desde sus orígenes y que va a reactivar el círculo vicioso que vincula deterioro, conflicto y estigma. Hacemos referencia al desmantelamiento del poblado chabolista del entorno de Bermejales y al cuestionable procedimiento de desalojo efectuado por el Ayuntamiento a través de su Gerencia de Urbanismo (Torres 2011). Tras la entrega del dinero comprometido a las familias afectadas, la mayor parte de ellas decidieron instalarse en Murillo, lo que tendrá graves secuelas para la convivencia vecinal.

Al margen de estos importantes acontecimientos, poco años después de su constitución y desarrollo, Comisionado y Plan Integral son valorados críticamente por actores muy representativos del tejido asociativo. Su burocratización, la perspectiva funcionarial y el nuevo modelo de gestión compartida, quedan muy alejados de las vivencias y la realidad cotidiana del vecindario, así mismo, "no se priorizan necesidades ni se fijan estrategias a corto y medio plazo para intervenir y no se ofrecen suficientes cauces de participación en este sentido" (Martín 2020, 521).

\section{4a. Etapa, 2008-2020. El Plan Integral frente a la crisis}

A partir del estallido de la burbuja inmobiliaria, la subsiguiente crisis económica no solo extiende la pobreza y agrava las situaciones de vulnerabilidad social, también va a profundizar en los desequilibrios interregionales y en las enquistadas desigualdades urbanas existentes en Andalucía. De acuerdo con el indicador AROPE (I.N.E.), que mide la tasa de riesgo de pobreza o exclusión social, la divergencia entre esta comunidad autónoma y el conjunto del Estado se hecho evidente en los momentos más duros de la crisis ${ }^{9}$, no reduciéndose sin embargo al mismo nivel cuando la situación general ha mejorado, al menos desde el punto de vista macroeconómico y del desempleo (Llano 2017).

En esta etapa continúan desplegándose, dentro del escenario global de crisis, iniciativas típicas del empresarialismo urbano y estrategias inherentes al modelo pretendido de city marketing. La profunda remodelación de la plaza y mercado de la Encarnación para construir el costoso Metropol Parasol ("Las Setas") entre 2005 y 2011, o el polémico proyecto de la Torre Pelli, rascacielos promovido por Cajasol que finaliza en 2015, pueden ser ejemplos paradigmáticos en este sentido. Por otro lado, hay que recordar que, desde 2006, el planeamiento urbanístico, influido por la tendencia general descrita, es dependiente de un nuevo Plan General.

En el ámbito interno de Polígono Sur, después de los sucesos ya comentados que tuvo que enfrentar la figura del Comisionado, la nueva situación económica general va a limitar sustantivamente las posibilidades de un Plan Integral cuyas directrices se habían establecido

9 Tal como recogen algunos medios en prensa, el reciente informe del relator de la ONU para la extrema pobreza, Philip Alston, destaca varios aspectos principales que subrayan la profunda desigualdad existente en el país ("Hay dos Españas y una está al límite": Diario de Sevilla, 07-02-2020) y el modo en que la Administración ha fallado a las personas que viven en la pobreza. En el caso concreto de Polígono Sur, el relator señaló entre otras cuestiones el modo en que se reproduce la segregación social en los centros educativos y los problemas de absentismo y fracaso escolar. 
en la etapa previa a la crisis. No obstante, entre las intervenciones que se inician, sobresalen algunas de carácter urbanístico y que resultan de gran interés para afrontar la mejora de las condiciones residenciales en los vecindarios más necesitados. Entre 2008 y 2012 se desarrolla el Programa de Rehabilitación Integral de Polígono Sur, gestionado por la Empresa Pública de Suelo de Andalucía. Su objetivo será el de normalizar la ocupación de las viviendas para proceder a una rehabilitación integral. Además de estas y otras operaciones, desde el Comisionado se hacen grandes esfuerzos para que determinados servicios urbanos no se vean alterados y funcionen con cierta normalidad.

A partir sobre todo de 2013 se pone en marcha el Proyecto URBAN-Polígono Sur (Programa Operativo FEDER Andalucía, 2007-2013), contando con un presupuesto superior a los $12.500 .000 €$. Aunque comprende una gran cantidad de acciones, agrupadas en distintas líneas estratégicas, destacamos aquí la construcción de Factoría Cultural, un equipamiento socio-cultural ubicado en la zona más deprimida, concretamente en el extenso solar intermedio a los dos sectores de Martínez Montañés, que se concibe para acoger actividades muy diversas, algunas relacionadas con la cultura del flamenco, buscando adquirir con ello proyección en toda la ciudad, incluso a nivel metropolitano.

A pesar de todas estas actuaciones y mejoras, se trata de un periodo en el que la crisis muestra su mayor crudeza en términos sociales, también a causa de los recortes en el gasto público. Ello va a suponer que buena parte de las iniciativas programadas no puedan tener garantías de continuidad, un inconveniente muy grave en ámbitos urbanos tan necesitados como este. Aparte de ello, los problemas vinculados con el estado y uso de las viviendas persisten en muchos casos (falta de accesibilidad, hacinamiento, insalubridad...) así como la ocupación ilegal de las mismas, los enganches al suministro público de luz y agua, etc.

A lo anterior se suma un severo conflicto interno que afecta a la convivencia de muchas familias de la barriada Murillo y a la imagen que, desde los medios de comunicación, se sigue construyendo de Polígono Sur; hacemos referencia a los enfrentamientos entre clanes de etnia gitana que se producen tras el asentamiento de los chabolistas que provenían del poblado de Bermejales. Estos acontecimientos han generado un clima de violencia que se prolonga hasta la actualidad, situación divulgada con frecuencia en los medios de comunicación.

Dada la trascendencia de dichos sucesos, el fortalecimiento del estigma vinculado con la marginación social, el tráfico de drogas y la delincuencia va a continuar lastrando las posibilidades de revertir los estereotipos que se asocian con esta parte de Sevilla. En función de estos factores, documentos recientes como el Plan Local de Zonas Desfavorecidas de Sevilla (PLIZD), inciden en "la alta movilidad de la población en el barrio, en especial de las familias no gitanas con hijos e hijas pequeñas que residen en bloques conflictivos, ya que terminan trasladándose a otra parte de la ciudad en cuanto su situación se lo permite" (Ayuntamiento de Sevilla 2019, 45). Otros informes, como el elaborado para la Estrategia Regional Andaluza para la Cohesión e Inclusión Social (ERACIS) (Consejería de Igualdad y Políticas Sociales 2018), también reflejan la gravedad de un fenómeno que implica muchas veces la expulsión de vecinos y vecinas a causa de amenazas o extorsiones. 
Por otra parte, la presencia de inmigración extranjera también merece algunas consideraciones al respecto. Son los inmigrantes más pobres, de procedencias con menores niveles de desarrollo y mayores dificultades de integración, los que terminan residiendo en los sectores urbanos más baratos de la ciudad. Es así como periferia global y periferia local parecen converger en espacios con una rica diversidad sociocultural que, sin embargo, no logra prosperar frente a la pobreza y las dificultades que emanan de la marginación. Como señala el PLIZD, "las disputas o enfrentamientos que se están produciendo en los últimos años parecen relacionarse con los rasgos de xenofobia mutua que surgen entre la comunidad gitana y la población africana" (Ayuntamiento de Sevilla 2019, 48).

Por último, desde el ámbito sociopolítico, la creación del Comisionado y la ejecución de los distintos proyectos del Plan Integral, conducen a un comportamiento diferenciado en organizaciones sociales y tejido asociativo. Mientras que, por una parte, se ha producido una adhesión funcional a los requerimientos del Plan, colaborando por ejemplo en la llamada Red de Entidades, por otro lado, han seguido realizándose reclamaciones y manifestaciones críticas respecto a la labor de las administraciones. La aplicación de una mirada sistémica e integrada a la hora de valorar la implicación de actores en el Plan Integral, pone de relieve un descontento generalizado con los resultados y con una estructura del Comisionado "que no ha conseguido generar un entendimiento común ni contar con el respaldo político necesario" (Gallego 2016, 70).

Entidades como las agrupadas en NtSS, que ponen el acento en combatir la inseguridad e impunidad, se vinculan con la Coordinadora Andaluza de Barrios Ignorados para difundir, desde una escala territorial más amplia y una incidencia social y política diferente, las necesidades que siguen presentando las zonas más desfavorecidas de Andalucía. Recientemente, en 2020, se han encauzado las reivindicaciones en función de los graves perjuicios que en ellas ha generado la pandemia del COVID-19 y las medidas de confinamiento adoptadas.

\section{A modo de conclusión: el perpetuo confinamiento de Polígono Sur}

Actualmente, el complicado contexto sociosanitario y económico que ha deparado la pandemia del COVID-19 en 2020, incide mayormente en los grupos sociales más humildes y en las áreas urbanas más desfavorecidas de nuestras ciudades. Las medidas de confinamiento dificultan la práctica de una economía sumergida, como la venta ambulante, que tiene especial implantación en estos barrios, reduciendo aún más los recursos de hogares que sufren carencias en muchos aspectos; del mismo modo, la población empleada suele vincularse con sectores como el de servicios, que han manifestado su evidente fragilidad al respecto.

Así mismo, las situaciones de emergencia social durante la pandemia se han puesto de relieve en Polígono Sur, aunque también en otros barrios sevillanos como Torreblanca o Tres Barrios-Amate. Entre los asuntos que destacan las notas de prensa de organizaciones sociales se encuentran los problemas de hacinamiento, la alimentación de los menores o la complicada gestión de los servicios sociales. El confinamiento ha provocado una enorme dependencia de los recursos informáticos y de unos mínimos conocimientos telemáticos. En 
estas circunstancias, en las que muchas familias carecen de ellos y donde la comunicación directa o presencial resulta de vital importancia por muchos y distintos motivos, la educación y la atención sanitaria se han visto también especialmente afectadas.

Estos dos primeros párrafos de las conclusiones son expresivos de la gravedad que ha presentado la situación de pandemia, no obstante, este particular confinamiento experimentado en el barrio puede también comprenderse como un nuevo y duro golpe dentro de su larga historia de marginación social y urbana...

La desigualdad urbana en Sevilla se ha enquistado desde los años ochenta hasta la actualidad, hecho que se ha puesto de relieve a partir de los análisis geoestadísticos efectuados gracias, principalmente, a los datos ofrecidos por los distintos censos y a los tratamientos cuantitativos multidimensionales de diversos trabajos. Así mismo, la evolución que ha experimentado Polígono Sur a lo largo de las etapas definidas, permite corroborar nuestra tesis acerca de un complejo proceso que, interpretado metafóricamente mediante una espiral con trayectoria descendente y aparente forma de embudo, expresa el estancamiento, cuando no declive, que sufre la situación social de esta área de la ciudad.

En este sentido, los aspectos físico-urbanísticos (urbs), los de carácter social y comunitario (civitas), así como los que conciernen al ámbito político y reivindicativo (polis), observados desde diferentes escalas geográficas (generales y externas a la ciudad, comunes a nivel municipal y metropolitano, e internas o endógenas del barrio) han establecido interrelaciones entre sí que, en conjunto, han obstaculizado determinadas posibilidades $u$ oportunidades de integración. En los sucesivos momentos, se ha ido consolidando así una segregación cada vez más acusada que deviene en una paulatina conversión de la pobreza en vulnerabilidad y de esta en exclusión social, terreno por otra parte abonado para la extensión de la marginación y delincuencia.

Si inicialmente, hasta la colmatación residencial del área, la fragmentación urbana y zonificación social se vinculan con evidentes operaciones de especulación urbanística, a lo largo de las décadas de los ochenta y noventa otras coyunturas sociales, económicas e institucionales van a influir en el abandono y degradación de este sector periférico de la ciudad. Desigualdad y segregación se retroalimentan en una estructura social urbana donde algunos límites cobran carácter de frontera, como sucede con el trazado ferroviario que separa Polígono Sur del vecino barrio de Bami. Se va definiendo así un mapa de precios que, sustentado también en la poderosa influencia del imaginario social y sus estereotipos, va a condicionar las opciones de movilidad residencial y a propiciar fenómenos como el de "invasión y sucesión”, característicos de espacios donde domina el desarraigo y los problemas de convivencia.

Nos encontramos ante una dialéctica general, inherente a dinámicas de nivel municipal y metropolitano, en la que los intereses del mercado inmobiliario y las necesidades de vivienda y hábitat, no son reconducidos por una política urbana tendente a la cohesión territorial y la inclusión social. La extensión de urbanizaciones cerradas y excluyentes, la gentrificación que sufren los barrios históricos, las intervenciones sobre los poblados chabolistas, con cuestionables medidas de desalojo -y de realojo cuando se producen-, la limitada política municipal de vivienda o la sobrerrepresentación de algunas áreas frente a 
la invisibilización de otras por parte del modelo empresarialista, son cuestiones que van a influir notablemente en la segregación socioespacial.

Dicha dialéctica general, condicionante de la estructura social urbana, entronca con la dialéctica interna que experimenta el barrio, y que se reproduce a partir de las relaciones antes descritas (urbs-civitas-polis). El descontrol institucional del traspaso de viviendas y la implantación del tráfico de drogas, que adquiere una dimensión prácticamente subregional, y otras actividades delictivas, sobre todo en las barriadas más aisladas y conflictivas, pueden ser dos de los factores más influyentes en este sentido.

Desde la conformación del Comisionado a comienzos del actual siglo, la puesta en marcha del Plan Integral no ha logrado revertir y superar estos procesos. Si bien, gracias a múltiples proyectos e inversiones, se han ampliado las oportunidades de mejora en las condiciones de vida de muchas familias, no puede decirse que en general se haya transformado la realidad social y urbana de Polígono Sur, más bien continúa estancada con nuevas tendencias de deterioro, tal como lo confirman los indicadores de renta publicados y los informes recientes de las administraciones autonómica y local (Consejería de Igualdad y Políticas Sociales 2018, Ayuntamiento de Sevilla 2019). Expresivas de esta circunstancia son también las necesidades que siguen desvelando centros de salud, centros educativos y de servicios sociales, la degradación del paisaje urbano o la delincuencia instalada. También lo interpretan así asociaciones y entidades vecinales aglutinadas en la plataforma NtSS o la visita del relator de la ONU sobre la Pobreza.

\section{Bibliografía}

Arenas Posadas, Carlos. 2016. Poder, economía y sociedad en el sur. Historia e instituciones del capitalismo andaluz. Sevilla: Centro de Estudios Andaluces, Consejería de la Presidencia y Administración Local (Junta de Andalucía)

Arias Goytre, Félix (coord.). 2000. La desigualdad urbana en España. Madrid: Ministerio de Fomento.

Ayuntamiento de Sevilla. 2019. Plan Local de Intervención en Zonas Desfavorecidas de Sevilla, 2018-2022.

Ayuntamiento de Sevilla - Servicio de Estadística. Explotación estadística de los datos del Padrón de Habitantes y del Callejero. https://www.sevilla.org/servicios/servicio-deestadistica/

Camacho Herrera, Antonio José. 1996. Movimiento vecinal y cambio social. Tesis doctoral inédita. Sevilla: Facultad de Ciencias de la Educación.

Capel Sáez, Horacio. 2003. “A modo de introducción: los problemas de las ciudades. Urbs, Civitas y Polis". Mediterráneo económico. Ciudades, arquitectura y espacio urbano 3, 922. https://dialnet.unirioja.es/servlet/articulo?codigo=2159515

Carmona Gallego, José. 2008. "Hacia el Polígono Sur 'Imposible' que queremos. Algunas reflexiones sobre los procesos de desarrollo en la transformación del barrio". Revista cuchará y paso atrá 19: 7-22. https://cuchara.ilusionismosocial.org/ 
Coca Pérez, Agustín. 2001. “Marginación social y estigma en Rabesa (Alcalá de Guadaíra)”. En Espacio y estigma en la Corona Metropolitana de Sevilla, Ruiz Ballesteros, E. (coord.), 99-116. Sevilla: Universidad Pablo de Olavide.

Comisionado para el Polígono Sur. 2013. Memoria del Plan Integral Polígono Sur, 2006-2011. Sevilla: Administración General del Estado, Junta de Andalucía, Ayuntamiento de Sevilla. https://www.juntadeandalucia.es/organismos/sobrejunta/planes/detalle/61764.html

Conde, Fernando. 2007. "Entre el arraigo y la movilidad. La importancia de los imaginarios sociales en la movilidad residencial". En La vivienda y el espacio residencial en las áreas metropolitanas, editado por José María Feria Toribio, 53-71. Sevilla: Centro de Estudios Andaluces.

Consejería de Igualdad y Políticas Sociales. 2018. Estrategia Regional Andaluza para la Cohesión e Inclusión Social - Intervención en Zonas Desfavorecidas. https://www.juntadeandalucia.es/organismos/igualdadpoliticassocialesyconciliacio n/areas/inclusion/paginas/dise\%C3\%B1o-ejecucion-estrategias.html

Díaz Parra, Ibán. 2010. Sevilla, cuestión de clase. Una geografía social de la ciudad. Sevilla: Atrapasueños.

Egea Jiménez, Carmen y Nieto Calmaestra, José Antonio. (coords.). 2015. Quién vive dónde. Las condiciones de habitabilidad de la población que vive en las grandes ciudades andaluzas. Granada: Universidad de Granada. http://condicionesdehabitabilidad.com/

Egea Jiménez, Carmen, Nieto Calmaestra, José Antonio, Domínguez Clemente, Javier y González Rego, René A. 2008. Vulnerabilidad del tejido social de los barrios desfavorecidos de Andalucía. Análisis y potencialidades. Sevilla: Centro de Estudios Andaluces, Junta de Andalucía. https://www.centrodeestudiosandaluces.es/datos/factoriaideas/ifo11_08.pdf

Gallego Gamazo, Cristina. 2016. "Análisis de la implicación de la diversidad de actores en el Plan Integral del Polígono Sur: una mirada sistémica e integrada". Hábitat y Sociedad 9: 55-74. http://dx.doi.org/10.12795/HabitatySociedad.2016.i9.04

Guerrero Mayo, María y López Igual, Purificación. 2012. "Políticas urbanas en la ciudad de Sevilla". Geopolítica(s). Revista de Estudios sobre Espacio y Poder 3(1): 61-81. https://doi.org/10.5209/rev_GEOP.2012.v3.n1.38987

Harvey, David. 1977. Urbanismo y desigualdad social. México: Siglo XXI.

Harvey, David. 2004. La condición de la posmodernidad. Investigación sobre los orígenes del cambio cultural. Buenos Aires: Amorrortu editores.

Instituto Nacional de Estadística. 2019. Atlas de Distribución de Renta de los Hogares. Proyecto técnico. Subdirección General de Estadísticas Sociodemográficas. https://www.ine.es/experimental/atlas/exp_atlas_proyecto.pdf

Instituto Nacional de Estadística. 2020. Indicadores Urbanos. Edición de 2020. Subdirección General de Estadísticas Sociodemográficas. https://www.ine.es/ss/Satellite?L=0\&c=INEPublicacion_C\&cid=1259944561392\&p $=1254735110672 \&$ pagename=ProductosYServicios\%2FPYSLayout 
Jaraíz Arroyo, Germán y Cañestro Fernández, Gonzalo. 2006. "La Sevilla solidaria y cotidiana”. En Mesa 4 del Prediagnóstico para la Revisión del Plan General de Ordenación Urbana de Sevilla, 119-137. Sevilla: Oficina del Plan de Sevilla, Ayuntamiento de Sevilla

Llano Ortiz, Juan Carlos. 2017. El estado de la pobreza. Seguimiento del indicador de riesgo de pobreza y exclusión en España, 2009-2016 (7ํ Informe). Madrid: EAPN - España. https://www.eapn.es/publicaciones/324/vii-informe-el-estado-de-la-pobreza

Machuca, Manuel. 2016. Tres mil viajes al sur. Sevilla: Anantes.

Marín de Terán, Luis. 1980. Sevilla, centro urbano y barriadas. Sevilla: Servicio de publicaciones del Ayuntamiento de Sevilla.

Martín Valverde, Luis. 2020. Recuerdos y confidencias de Nolasco Santoro.

Ministerio de Fomento. 2015. Atlas de la Vulnerabilidad Urbana en España 2001 y 2011. Metodología, contenido y créditos. http://atlasvulnerabilidadurbana.fomento.es/

Nijman, J., \& Wei, Y. D. 2020. "Urban inequalities in the 21st century economy". Applied geography (Sevenoaks, $\quad$ England) 117: 102-188. https://doi.org/10.1016/j.apgeog.2020.102188

Soja, Edward. 1980. "The Socio-Spatial Dialectic". Annals of the Association of American Geographers 70: 207-225. https://www.jstor.org/stable/2562950

Soja, Edward. 2008. Postmetrópolis. Estudios críticos sobre las ciudades y las regiones. Madrid: Traficantes de Sueños.

Tammaru, Tiit, Marcińczak, Szimon, Van Ham, Maarten y Musterd, Sako. (eds.). 2016. SocioEconomic Segregation in European Capital Cities. London: Routledge.

Torres Gutiérrez, Francisco José. 2011. "El territorio de los desheredados. Asentamientos chabolistas y experiencias recientes de erradicación en Sevilla". Hábitat y Sociedad 3: 67-90. http://dx.doi.org/10.12795/HabitatySociedad.2011.i3.05

Torres Gutiérrez, Francisco José. 2013. Segregación urbana y exclusión social en Sevilla. El paradigma Polígono Sur. Sevilla: Universidad de Sevilla y Fundación Focus-Abengoa.

Torres Gutiérrez, Francisco José y García Herrera, Luz Marina. 2011. "Metodologías para el análisis de la desigualdad urbana y la exclusión social. Aplicación al caso de la ciudad de Sevilla y sus barrios". Revista ERÍA (84-85): 103-108. https://dialnet.unirioja.es/servlet/articulo?codigo $=3817701$

Vorauer, Markus. 2011. "Las 3.000". Segregación social en el espacio urbano. Sevilla: Universidad de Sevilla y Consejería de Obras Públicas y Viviendas (Junta de Andalucía). 
(C) Copyright: Francisco José Torres Gutiérrez, 2021

(C) Copyright: Scripta Nova, 2021.

Ficha bibliográfica:

TORRES GUTIÉRREZ, Francisco José. Polígono sur en Sevilla. Historia de una marginación urbana y social. Scripta Nova. Revista Electrónica de Geografía y Ciencias Sociales. Barcelona: Universitat de Barcelona, vol. 25, Núm. 1 (2021), p. 105-129 [ISSN: 1138-9788]

DOI: $10.1344 / \mathrm{sn} 2021.25 .33352$ 